International Journal of Social and Administrative Sciences

$\operatorname{ISSN}(e): 2521-0556$

DOI: $10.18488 /$ journal.136.2020.52.94.108

Vol. 5, No. 2, 94-108.

(C) 2020 AESS Publications. All Rights Reserved.

URL: www.aessweb.com

check for
updates

\title{
ROLE-BASED STRESS AND BURNOUT AMONG NIGERIAN SAMPLE: THE MODERATING ROLE OF SELF-EFFICACY
}

\author{
Dynthia C. Ugwu' \\ Ejike A. \\ Okonkwo $^{2+}$ \\ Celestine I. \\ Ngwoke $e^{s}$
}

\author{
${ }^{1,2}$ Department of Psychology, Enugu State University of Science and \\ Technology, Nigeria. \\ 'Email:ugrou772@gmail.com Tel:07062501629 \\ ${ }^{2}$ Email:aejyke@yahoo.com Tel: osos7431759 \\ ${ }^{s}$ Department of Educational Foundation, University of Nigeria Nsukka, \\ Nigeria. \\ 'Email:celestinengwoke@gmail.com Tel: 08066757416
}

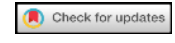

(a)

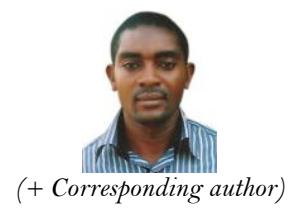

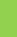

\section{Article History}

Received: 19 June 2020 Revised: 21 July 2020 Accepted: 23 August 2020 Published: 17 September 2020

\section{Keywords}

Role-based stress Burnout Self-efficacy Nurses

Moderating role Relations.

\begin{abstract}
There has been much research linking role-based stress to burnout among nurses, but there has been little effort to study the moderating role of self-efficacy in this link in the Nigerian nurses. Considering the theoretical assumptions of the job demand-resources model linking role-based stress and self-efficacy to burnout, this cross-sectional study investigated the moderating role of self-efficacy in role-based and burnout relations among nurses in Enugu urban area of Enugu State, Nigeria. One hundred and seventy (170) nurses, comprising 43 males and 127 females between the ages of 22 to 55 years were sampled using multi-stage sampling techniques. The 15-item Job Tension Scale, 22-item Burnout Inventory and 10-item Generalized Self-efficacy Scale were administered for data collection. Results of moderated regression analysis revealed that role-based stress and emotional self-efficacy did not equally predict the components of burnout. Self-efficacy positively moderated only feeling of reduced personal accomplishment component of burnout. Role-based stress and self-efficacy accounted for $3.1 \%$ of the variance in emotional exhaustion of the nurses, $11.8 \%$ of variance in dehumanization and $35.3 \%$ in feeling of reduced personal accomplishment. Specifically, role-based stress independently and positively predicted feeling of reduced personal accomplishment but not emotional exhaustion and dehumanization. Self-efficacy independently and negatively predicted emotional exhaustion, dehumanization and feeling of reduced personal accomplishment. The study has recommended that policy makers in nursing/health sector should reduce role-based stress while enhancing selfefficacy in order to reduce burnout.
\end{abstract}

Contribution/ Originality: This study is one of very few studies which have investigated the moderating role of self-efficacy in the relationship between role-based stress and burnout among nurses in a non-Western context.

\section{INTRODUCTION}

The role responsibilities of the helping professionals such as nurses occupy the major part of their lives in terms of time, effort and importance which may result in role-based stress and likely make them vulnerable to burnout, hence the need for the present study. Moreover, burnout is a topic of major interest because it has consequential implications for both individuals and organizations (Cropanzano, Rupp, \& Byrne, 2003). From individual perspective, burnout is related to a myriad of health related issues, including anxiety, depression, 
headaches and sleep disturbances (Wright \& Bonnet, 1997). From organizational perspective, burnout is linked with intentions to turnover, decreased level of commitment and job satisfaction (Jackson, Schwab, \& Schuler, 1986).

Giving credence to this study focusing on nurses, Freudenberger (1974) coined the term "burnout" to describe workers' reactions to the chronic stress common in occupations involving numerous direct interactions with people such as nursing profession characterized by emotionally demanding situation. In line with this, studies (e.g. Anderson, 2013; Pines and Aronson (1988)) suggest that burnout is a state of physical, emotional and mental exhaustion caused by long term involvement in situations that are emotionally demanding. According to Winstanley and Whittington (2002) burnout is a process associated with stress and deriving from a combination of low coping mechanisms and high workload. Burnout is often found among those working in very demanding professions (e.g. nursing) or those who work strenuous multiple jobs, thus, the stress that people in the nursing profession experience is an important topic for study. The nursing profession usually involves high interpersonal or emotional demands, which can lead to feelings of emotional exhaustion, feelings of reduced personal accomplishment and depersonalization (Kirwan \& Armstrong, 1995; Winefield \& Anstey, 1991) which are characteristics of burnout.

Maslach and Jackson (1986) identified emotional exhaustion, depersonalization or dehumanization; and a reduced sense of personal accomplishment as burnout dimensions. Emotional exhaustion is the central dimension of burnout, and it is characterized by a feeling that one's emotional resources are used up (Maslach \& Jackson, 1986; Maslach, Schaufeli, \& Leiter, 2001). It refers to the feelings of over-extension and exhaustion resulting from daily conflict in work environment. Emotional exhaustion can occur when workers' resources are depleted and they feel that they are no longer able to give themselves at a psychological level (Maslach \& Jackson, 1986; Maslach et al., 2001).

Depersonalization is a cynical, callous and detached attitude toward clients, co-workers, organization and even self (Cordes \& Dougherty, 1993). It indicates the development of negative attitudes and impersonal behaviors to people in relation to the profession. It is also the emotionally dry and detached manner of relating to others (Maslach \& Jackson, 1986; Maslach et al., 2001). For those who deal with people on a day to day basis (e.g. nurses), it entails treating individuals (e.g. patients) as object rather than people.

Reduced sense of personal accomplishment is a decline in ones feelings of competence and successful achievement (Leiter \& Maslach, 1988). The sense of personal fulfillment is likely to be negatively related to burnout; the more people suffer from burnout, the worse they feel about their personal accomplishment. It is marked by a sense of ineffectiveness and inadequacy in relation to job performance accompanied by negative selfevaluation (Togia, 2005).

Theoretically, job demand-resources model (Bakker, Demerouti, \& Schaufeli, 2003) suggests that burnout is a consequence of the perceived disparity between the demands of the job and the resources (both material and emotional) that an employee has available to him or her. And this disparity may trigger role-based stress since burnout is a type of stress response that is on the rise among workers and most common among those who have intense contact and involvement with others (e.g. nurses) during the course of their normal workday (Lee \& Ashforth, 1990). Moreover, human service workers (e.g. nurses) build unrealistic expectations regarding what it means to be a professional which triggers stress, hence making them susceptible to burnout (Nwabuoku \& Adebayo, 2010). This has shown the link between the stress emanating from the roles of nurses and their experience of burnout. In support of this, Kahn and Byosiere (1997) defined role-based stress as the feelings of tension, discomfort, uncertainty, indecisiveness and distress that a worker experiences as a result of the social and physical circumstances of the work setting. Role-based stress is the stress emanating from the demands of the job (E. Okonkwo, 2013) which may vary across work settings. For example, studies (e.g. Maslach et al. (2001)) on causes of psychosocial stress indicate that many occupational settings are potentially stressful. Interestingly, the nursing profession is among the potentially stressful occupational settings. However, Niosh (1995) stated that many role- 
based stress also favor individual characteristics such as personality, thus indicating that certain working conditions are stressful to some people (Elisburg, 1995). And role-based stress occurs in a wide range of work circumstances but is often made worse when employees feel they have little resources such as self-efficacy which is a reflection of personality attributes (Bakker et al., 2003), thus the interest of this study in self-efficacy as a moderator.

Self-efficacy is a personality variable reflecting a person's optimistic self beliefs about being able to deal with critical demands by means of adaptive actions (Schaufeli \& Greenglass, 2001). According to Bandura (1997) selfefficacy is belief in one's own capacity to organize and execute the courses of action required to manage prospective situations. In the light of role-based stress and burnout, self-efficacy represents the confidence that one can employ the skills necessary to deal with job specific tasks and cope with job specific challenges, job- related stress and its consequences (Shoji et al., 2016). Lending support to this view, a low sense of self- efficacy is associated with depression, anxiety, helplessness and burnout (Schwarzer, 1999). Similarly, studies (e.g. (Brief \& Aldag, 1989; Jex \& Bliese, 1999; Shoji et al., 2016)) have shown that self-efficacy may operate as a resource preventing the negative consequences of stress and burnout, thus, self-efficacy prompting recovery from job stress and burnout(Hahn, Binnewies, Sonnentag, \& Mojza, 2011). Further studies (e.g. Jimmieson, Terry, and Callan (2004)) found efficacy beliefs to facilitate employee's adaptation to changes in the organization. And for nurses, self-efficacy is a likely very important personal resource, since they are often exposed to high job stress, and long term job stress leads to burnout. Nurses who have high levels of self-efficacy might be more capable of selecting, altering and implementing their resources to meet stressful demands. Self-efficacy may determine the way employees (nurses) perceive existing job demands and available job resources which in turn, may have an effect on their levels of wellbeing and burnout (Hobfoll, 1989) hence the focus of this present study on self-efficacy as a moderator.

\subsection{Theoretical Overview and Hypothesis Development}

Bakker et al. (2003) job demand-resources model is arguably one of the important theories linking role-based stress and self-efficacy to burnout. Job demand-resources theory suggests that there is an underlying relationship in which an individual's physical and psychological well-being are the consequences of two comparatively autonomous processes (Bakker et al., 2003). In the first process, the challenging components of work such as overload, lead to overtaxing of the resources causing role-bases stress and eventually burnout. To this end, the progression of burnout follows two routes; the first beings with the high demands of the job which leads to exhaustion and the second begins with limited resources which makes it challenging to fulfill the demands required by the job. During the second process the presence of job resources and personal resources such as self-efficacy assist individuals to manage the challenging components of their role responsibilities, thus reducing role-based stress which would have caused burnout. In this case, employees facing high role-based will be less exhausted when sufficient job and personal resources are available (Bakker et al., 2003).

In congruence with Bakker et al. (2003) model, conservation of resources theory (Hobfoll, 1989) suggests that individuals strive to obtain and maintain what they prize or value- resources. And burnout among nurses is most likely to occur in situations where there is an actual resource loss/perceived threat of resource loss; a situation in which one's resources (e.g. self-efficacy) are inadequate to meet work demands, or when the anticipated returns are not obtained on an investment of resources (Hobfoll, 1988; Lee \& Ashforth, 1996).

\subsection{Role-Based Stress and Burnout}

The link between role-based stress and burnout has been demonstrated in numerous studies. For example, Xie, Wang, and Chen (2011) in a study investigated nurse burnout and its association with occupational stressors in Shanghai China using 527 nurses from 41 hospitals. The result showed that nurses suffered from high level of burnout, which was strongly associated with work-related stress. Similarly, Stordeur, D'hoore, and Vandenberghe (2001) in a study of 625 nurses found work stressors to account for $22 \%$ of the variance in emotional exhaustion 
component of burnout. In contrast, Enukorah (2010) in another study involving nurses from two hospitals in Enugu State, Nigeria found no significant influence of role stress on burnout.

Woodhead, Northrop, and Edelstein (2004) in a study of 250 nurses that job demands (greater occupational stress) where associated with more emotional exhaustion, more depersonalization and less personal accomplishment components of burnout. Tuna and Baykal (2014) in another study of 189 nurses from 11 hospitals in Istanbul investigated the relationship between work stress and burnout. Results of the study showed a positive weak correlation between work role ambiguity dimension of job stress, emotional exhaustion and personal accomplishment, where as a positive weak and medium correlation was found between work role conflict dimension, emotional exhaustion and depersonalization. And a negative weak correlation was found between work role overload dimension, emotional exhaustion and depersonalization.

In study conducted by Morana, Branko, Dinko, and Vanja (2014) on stress and burnout among hospital physicians in Rijeka Croatia using 459 hospital physicians reported that most of the perceived stressors were significant predictors of burnout. Similarly, Garrosa, Moreno-Jiménez, Rodríguez-Muñoz, and Rodríguez-Carvajal (2014) in a cross-sectional data from 500 nurses from general hospital in Madrid, Spain found role stress as an important predictor of burnout. In a study involving 605 employees across several service organizations, Leiter and Maslach (1988) found that role conflict and role ambiguity at work accounted for significant amount of variance in the emotional exhaustion phase of the burnout process.

\subsection{Self-Efficacy and Burnout}

The relationship between self-efficacy and burnout has continued to attract the attention of researchers. For example, Salanova, Peiro, and Schaufeli (2002) in a study of 405 workers found self-efficacy to moderate the relationship between job demand-control and burnout. Similarly Jex and Bliese (1999) found that self-efficacy has a moderating role on some pointers of burnout such as organizational commitment, physical symptoms and attempts to abandon the job. And high levels of self- efficacy was related to less burnout, while low level of self-efficacy was related to high burnout. Wright, Scott, and Rose (2015) found self-efficacy to moderate the relationship between exposure to violence, depersonalization and emotional exhaustion.

Eze (2014) in another research on the influence of self-efficacy on burnout among 209 nurses in Umuahia Nigeria found slight difference in the burnout between nurses with low self-efficacy and those with high selfefficacy. Alidosti, Delaram, Dehgani, and Moghadam (2016) in a study on the relationship between self-efficacy and burnout among nurses in Behbahan city Iran using 151 nurses found a significant inverse relationship between selfefficacy and burnout. Similarly Pisanti et al. (2015) in their study of 1479 nurses found that occupational coping self-efficacy buffers the association between low control and distress dimensions, emotional exhaustion and depersonalization.

Shoji et al. (2016) in a meta-analysis of 57 original studies conducted among teachers, health care providers and other professionals. They concluded that significant self-efficacy-burnout relationship was observed across countries although the strength of association varied across burnout dimensions. Aftab, Ali Shah, and Mehmood (2012) investigated the relationship between burnout and self-efficacy among physicians working in different hospitals in Pakistan. Results showed a significant negative relationship between self-efficacy, emotional exhaustion and depersonalization, and a positive significant relationship between self-efficacy and personal accomplishment.

\subsection{Self-Efficacy and Role-Based Stress}

The relationships between self-efficacy and role-based have been found in numerous studies. For example, Lu, Yueh, and Lune (2011) in a study of 310 full time employees across all regions of Taiwan showed self efficacy to buffer the negative impact of lack of autonomy on job stress. 
Grau, Salanova, and Peiró (2001) investigated self-efficacy as a moderator of occupational stress process among 140 employees. The results showed that self-efficacy moderated the stress-strain relationship in general, in the sense that low levels of self-efficacy are related to high level of occupational stress and burnout dimensions. Similarly, Thompson and Gomez (2014) in a study of 78 employees found self-efficacy to moderate the relationship between workplace stressors and strain. Kelly, Wanyne, Pamela, Angela, and Christian (2001) in a study investigated the potential moderating influence of collective efficacy on role conflict -work outcomes relationships job satisfaction, intent to turnover and exhaustion, using 188 nurses. Results showed that individuals reported lower levels of exhaustion, role conflict and turnover intent, when collective efficacy was perceived to be high.

\subsection{Nigerian Context}

Relying on institutional theory (Scott, 2005) it is suggested that institutions and people in other national contexts especially developing countries may be exposed to different factors which influence their management practices. And these management practices in developing countries such as Nigeria may have implications for the outcome of studies involving Nigerian organizations; hence consideration of previous studies on burnout of a developing nation such as Nigeria where this present study is located is vital.

In line with this need, Enukorah (2010) in a study of nurses drawn from two hospitals in Enugu State, Nigeria found that those who experienced high level of role-based stress are likely to become victims of psychological burnout and consequently may become seriously impaired in health, social and occupational functioning (Enukorah, 2010). Eze (2014) in another research investigated the influence of perceived organizational support on burnout among 209 nurses in Umuahia, Nigeria. Results showed that nurses with low perceived organizational support experienced high level of burnout than those with high perceived organizational support. Tunde and Onabanjo (2013) found significant differences between the levels of self-esteem and personality differences in the teachers' proneness to burnout syndrome. Despite the fact that all these previous studies including others (e.g. (Anomneze, Ugwu, Enweruzor, \& Ugwu, 2016; Okonkwo, 2013; Okonkwo, 2014; Okonkwo, Onuibe, Okoro, \& Madu, 2015)) focused on burnout in Nigerian samples, there have, ironically, been no studies of these concerns in Nigerian context considering the moderating role of self-efficacy in role-based stress and burnout. This research gap is particularly problematic and calls for research involving African population, hence this present study in nonWestern context of Nigeria testing the following hypotheses.

1. Role-based stress will be positively related to emotional exhaustion aspect of burnout.

2. Self-efficacy will be negatively related to emotional exhaustion aspect of burnout.

3. Self-efficacy will weaken the positive relationship between role-based stress and emotional exhaustion aspect of burnout.

4. Role-based stress will be positively related to dehumanization aspect of burnout.

5. Self-efficacy will be negatively related to dehumanization aspect of burnout.

6. Self-efficacy will weaken the positive relationship between role-based stress and dehumanization aspect of burnout.

7. Role-based stress will be positively related to feeling of reduced personal accomplishment aspect of burnout.

8. Self-efficacy will be negatively related to feeling of reduced personal accomplishment aspect of burnout.

9. Self-efficacy will weaken the positive relationship between role-based stress and feeling of reduced accomplishment aspect of burnout.

\section{METHOD}

\subsection{Participants and Procedure}

Participants were 170 nurses comprising 43 males and 127 females between the ages of 22 to 55 years. Using multi-stage sampling techniques participants were drawn from two (2) hospitals in Enugu Urban, Enugu State, 
Nigeria. Permission for the conduct of the study using nurses from Enugu State was obtained from the Commissioner of Health, Enugu State.

The researchers identified with the Chief Medical Directors and Chief Nursing Officers of the two hospitals in order to inform them of the study and get their cooperation. Copies of the questionnaire were administered to the participants and instructions given. They were allowed to go home with the copies and returned on a later date. One hundred and eighty five (185) copies (92.5\%) of the questionnaire were returned and 15 (8.1\%) copies were discarded due to errors in completion, hence, $170(91.9 \%)$ copies of the questionnaire were scored and analyzed for hypotheses testing.

\subsection{Measures}

Three scales were used. They include 15-item Job-related Tension Scale (Kahn, Wolfe, Quinn, Snoek, \& Rosenthal, 1964) 22-item Burnout Inventory (Maslach \& Jackson, 1981) and Generalized Self-efficacy Scale (Schwarzer \& Jerusalem, 1995).

\subsection{Job-related Tension Scale}

Role-based scale was assessed using 15-item Job-related Tension Scale (Kahn et al., 1964). Sample item reads "Feeling that you have too heavy a work load, one that you can't possibly finish during an ordinary work day". There are only direct scoring items. Ratings were made using 5-point scale, ranging from 1 (Never) to 5 (Nearly all the time) with internal reliability coefficients of .78 and .39 reported by Oseghare (1988) in a Nigerian sample. Okonkwo, Egbujor, and Onyeneje (2018) reported Cronbach's alpha of .97. The present researchers also obtained Cronbach's alpha of .73 for the scale.

\subsection{Burnout Inventory}

Burnout was assessed using 22-item Burnout Inventory (Maslach \& Jackson, 1981). The scale has three subscales measuring emotional exhaustion, depersonalization and feeling of reduced personal accomplishment. Sample item for emotional exhaustion reads "I feel emotionally drained from my work". Dehumanization item reads "I worry that this job is hardening me emotionally". Feeling of reduced personal accomplishment item reads "I feel like I am at the end of my rope". There are both direct scoring and reverse scoring items. Ratings were made using 6-point scale ranging from 1 (a few times a year) to 6 (everyday) with Cronbach's alpha of .71 to .90 and the test retest reliability of .80 reported by Maslach and Jackson (1986). Coker (1999) also reported Cronbach's alpha of .86 and split half reliability coefficient of .57. Olebara and Okonkwo (2019) reported Cronbach's alpha of .72. The present researchers reported Cronbach's alpha of .81 .

\subsection{Generalized Self-Efficacy Scale}

Self-efficacy was assessed using 10-item Generalized Self-efficacy Scale (Schwarzer \& Jerusalem, 1995). Sample item reads of 'I can always manage to solve difficult problems if I try hard enough'. There are only direct scoring items. Ratings were made using 4-point scale, ranging from 1 (Not all time) to 4 (Exactly true) with Cronbach's alpha ranging from .75 to .90 reported by Schwarzer and Jerusalem (1995). Eze. (2019) in a Nigerian sample reported Cronbach's alpha of .72. The present researchers obtained Cronbach’s alpha of .78. 


\section{RESULTS}

Table-1. Descriptive Statistics and Correlations among the Study Variables for Emotional Exhaustion.

\begin{tabular}{|c|c|c|c|c|c|c|c|c|c|c|c|}
\hline Model & Variables & $\bar{M}$ & $\mathrm{SD}$ & 1 & 2 & 3 & 4 & 5 & 6 & 7 & 8 \\
\hline 1 & $\begin{array}{l}\text { Emotional } \\
\text { Exhaustion }\end{array}$ & 29.21 & 4.29 & 1 & & & & & & & \\
\hline 2 & Gender & .75 & .44 & $-19^{* *}$ & 1 & & & & & & \\
\hline 3 & Marital Status & .43 & .50 & .00 & .18 & 1 & & & & & \\
\hline 4 & Age & .45 & .50 & -.01 & -.15 & -.29 & 1 & & & & \\
\hline 5 & Years of Experience & .48 & .78 & $-.13^{*}$ & .04 & -.04 & .22 & 1 & & & \\
\hline 6 & Qualification & .79 & .79 & -.03 & -.03 & .06 & .07 & .30 & 1 & & \\
\hline & & & & & & & & & & & \\
\hline 7 & Role based Stress & 2.52 & .54 & .07 & -.01 & .04 & -.10 & .01 & .04 & 1 & \\
\hline 8 & Self-Efficacy & 31.16 & 6.02 & .09 & .15 & .01 & .06 & .06 & .09 & -.35 & 1 \\
\hline
\end{tabular}

Note: $*=P<.05, * *=P<.01$ and ${ }^{*} * * *=p<.001$. Gender was coded $0=$ Females, $1=$ Males; Marital status was coded $0=\operatorname{single,~} 1=$ married; Age was coded $0=$ Young, $1=$ Old; Years of Experience was coded $0=$ Short Years of experience, $1=$ Long Years of Experience and Qualification was coded $0=$ Low Qualification, 1 = High Qualification.

Results in Table 1 indicate that marital status, age, qualification, role-based stress and self-efficacy were not significantly related to emotional exhaustion aspect of burnout among nurses. However, gender $(r=-.19, p<.01)$ and years of experience $(r=-.13, p<.001)$ were significantly related to the emotional exhaustion aspect of burnout experienced by nurses, though, negatively. Meaning that, female nurse were more likely to experience emotional exhaustion than their male counterparts. Also long serving staff were less likely to experience emotional exhaustion than the short serving staff.

Table-2. Moderated regression showing the moderating role of self-efficacy in the relationship between role-based stress and emotional exhaustion.

$(\mathrm{N}=170)$

\begin{tabular}{l|c|c|c}
\hline \multirow{2}{*}{ Variable } & Step 1 & Step 2 & Step 3 \\
\cline { 2 - 4 } & B & B & B \\
\hline Gender & $-.19^{* *}$ & $-.23^{*} * *$ & $-.23^{* * *}$ \\
\hline Marital Status & .03 & .03 & .05 \\
\hline Age & .00 & -.01 & -.00 \\
\hline Years of Experience & -.12 & -.12 & -.14 \\
\hline Qualification & -.01 & -.02 & .00 \\
\hline Role-based Stress & & .15 & $.17^{*}$ \\
\hline Self-efficacy & & $-.13^{*}$ & .14 \\
\hline Moderation & & & -.13 \\
\hline $\mathrm{R}^{2}$ & .055 & .085 & .104 \\
\hline Adjusted $R^{2}$ & .026 & .046 & .059 \\
\hline$\Delta \mathrm{R}^{2}$ & .055 & .031 & .018 \\
\hline Note: $* p<.05 ; * *=p<.01 ; * * *=p<.001$. & & &
\end{tabular}

The results of the moderated hierarchical multiple regression in Table 2 indicate that the demographic variables: gender, marital status, age, years of experience and qualification entered in step 1 of the equation collectively accounted for $5.5 \%$ variance in emotional exhaustion aspect of burnout of nurses, with only gender $(\beta=$ $-.19, p<.01)$ making significant negative contribution to the prediction of emotional exhaustion. This suggests that males were less likely to experience emotional exhaustion than female nurses.

In step 2, when the predictor variables: role-based stress and self-efficacy were entered, as a block, they did not add significantly to the variance in emotional exhaustion aspect of burnout manifestation of nurses $\left(\Delta R^{2}=.031, F\right.$ $(2,162)=2.73, p>.05)$. Individually, role-based stress $(\beta=-.15, p>.05)$ did not contribute significantly to emotional exhaustion aspect of burnout manifestation among nurses but self-efficacy $(\beta=-.13, p<.05)$ did, thereby disconfirming hypotheses 1 and confirming hypothesis 2 . 
Finally, the interaction terms between the moderating (self-efficacy) and predictor (role-based) variables when entered as a block in step 3 of the regression model, added only $3.1 \%$ variance in emotional exhaustion component of burnout $\left(\Delta R^{2}=.031, \Delta F(1,161)=3.27, p>.05, \beta=-.143, \mathrm{t}(161)=-.181, p>.050\right)$. This insignificant contribution has indicated that self-efficacy did not moderate the relationship between role-based stress and emotional exhaustion, thus not confirming hypothesis 3.

Table-3. Descriptive statistics and correlations among the study variables for dehumanization.

$(\mathrm{N}=170)$

\begin{tabular}{|c|c|c|c|c|c|c|c|c|c|c|c|}
\hline Model & Variables & $\mathbf{M}$ & SD & 1 & 2 & 3 & 4 & 5 & 6 & 7 & 8 \\
\hline 1 & Dehumanization & 12.70 & 3.70 & 1 & & & & & & & \\
\hline 2 & Gender & .75 & .44 & $.24 * *$ & 1 & & & & & & \\
\hline 3 & Marital Status & .43 & .50 & .11 & .18 & 1 & & & & & \\
\hline 4 & Age & .45 & .50 & -.06 & -.15 & -.29 & 1 & & & & \\
\hline 5 & Years of Experience & .48 & .78 & .09 & .04 & -.04 & .22 & 1 & & & \\
\hline 6 & Qualification & .79 & .79 & -.02 & -.03 & .06 & .07 & .30 & 1 & & \\
\hline 7 & Role based Stress & 2.52 & .54 & .07 & -.01 & .04 & -.10 & .01 & .04 & 1 & \\
\hline 8 & Self-Efficacy & 31.16 & 6.02 & $-.16^{*}$ & .15 & .06 & .06 & .06 & .09 & -.35 & 1 \\
\hline
\end{tabular}

Results in Table 3, indicate that marital status, age, qualification, role based stress and years of experience were not significantly related to dehumanization aspect of burnout manifestation among nurses. Meanwhile, gender $(r=$ $.24, p<.01)$ and self-efficacy $(r=-.16, p<.05)$ were significantly related to the dehumanization aspect of burnout, positively and negatively respectively. These suggest that males experienced more dehumanization than their female counterparts. Self efficacy also related negatively to dehumanization, thus nurses with high self-efficacy experienced less dehumanization.

Table-4. Moderated regression showing the moderating role of self-efficacy in the relationship between role-based stress and dehumanization.

\begin{tabular}{|c|c|c|c|}
\hline \multirow[t]{2}{*}{ Variable } & Step 1 & Step 2 & Step 3 \\
\hline & B & B & B \\
\hline Gender & $.22^{* *}$ & $.25^{* *}$ & $.25^{* *}$ \\
\hline Marital Status & .07 & .08 & .08 \\
\hline Age & -.03 & -.01 & -.01 \\
\hline Years of Experience & .11 & .11 & .11 \\
\hline Qualification & -.05 & -.03 & -.02 \\
\hline Role based Stress & & -.00 & .01 \\
\hline Self-Efficacy & & $-.21^{* *}$ & $-.21^{* *}$ \\
\hline Moderation & & & -.07 \\
\hline $\mathrm{R}^{2}$ & $.072^{*}$ & .114 & 118 \\
\hline Adjusted $R^{2}$ & $.044^{*}$ & .076 & .074 \\
\hline$\Delta \mathrm{R}^{2}$ & $.072^{*}$ & .042 & .004 \\
\hline
\end{tabular}

The results of the moderated hierarchical multiple regression in Table 4 indicate that the demographic variables: gender, marital status, age, years of experience and qualification entered in step 1 of the equation collectively accounted for $7.2 \%$ variance in dehumanization aspect of burnout of nurses, with only gender $(\beta=.22$, $p<.01)$ making significant positive contribution to the prediction of dehumanization.

In step 2, when the predictor variables: role based stress and self-efficacy were entered as a block, they added significantly to the variance in dehumanization aspect of burnout $\Delta R^{\circ}=.042, F(2,162)=3.82, p=.02$. Individually, role-based stress $(\beta=-00, p>.05)$ did not contribute significantly to dehumanization aspect of burnout but selfefficacy $(\beta=-.21, p<.05)$ did, negatively, hereby disconfirming hypothesis 4 and confirming hypothesis 5 . 
More so, the interaction terms between the moderating (self-efficacy) and predictor (role-based) variables when entered as a block in step 3 accounted for $11.8 \%$ variance in dehumanization $\left(\Delta R^{2}=.004, \Delta F(1,161)=.702\right.$, $p>.05, \beta=-.07, \mathrm{t}(161)=-.83, p>.05)$. This insignificant contribution has indicated that self-efficacy did not moderate the relationship between role-based stress and dehumanization component of burnout, hence not confirming hypothesis 6 .

Table-5. Descriptive Statistics and correlations among the study variables for feeling of reduced personal accomplishments. $(\mathrm{N}=170)$

\begin{tabular}{|c|c|c|c|c|c|c|c|c|c|c|c|}
\hline Model & Variables & $\mathbf{M}$ & SD & 1 & 2 & 3 & 4 & 5 & 6 & 7 & 8 \\
\hline 1 & RPA & 23.78 & 6.94 & 1 & & & & & & & \\
\hline 2 & Gender & .75 & .44 & .11 & 1 & & & & & & \\
\hline 3 & Marital Status & .43 & .50 & -.08 & .18 & 1 & & & & & \\
\hline 4 & Age & .45 & .50 & .07 & -.15 & -.29 & 1 & & & & \\
\hline 5 & Years of Experience & .48 & .78 & .09 & .04 & -.04 & .22 & 1 & & & \\
\hline 6 & Qualification & .79 & .79 & $-.12 * *$ & -.03 & .06 & .07 & .30 & 1 & & \\
\hline 7 & Role based Stress & 2.52 & .54 & $-.29 * * *$ & -.01 & .04 & -.10 & .01 & .04 & 1 & \\
\hline 8 & Self-Efficacy & 31.16 & 6.02 & $-.46^{* * * *}$ & .15 & .06 & .06 & .06 & .09 & -.35 & 1 \\
\hline
\end{tabular}

Results in Table 5 indicate that gender, marital status, age and years of experience were not significantly related to feeling of reduced personal accomplishments aspect of burnout manifestation among nurses. Meanwhile, qualification $(r=-.12, p<.01)$, job stress $(r=.29, p<.001)$ and self-efficacy $(r=-.46, p<.001)$ were significantly related to the feeling of reduced personal accomplishments aspect of burnout, positively and negatively respectively. Meaning that, with lower qualification, higher role-based stress and lower self-efficacy, feeling of reduced personal accomplishments aspect increased.

Table- 6. Moderated regression showing the moderating role of self-efficacy in the relationship between role-based and feeling of reduced personal accomplishments

\begin{tabular}{|c|c|c|c|}
\hline \multirow[t]{2}{*}{ Variable } & Step 1 & Step 2 & Step 3 \\
\hline & B & B & B \\
\hline Gender & .12 & .1 & .19 \\
\hline Marital Status & -.07 & -.04 & -.06 \\
\hline Age & .06 & .12 & .11 \\
\hline Years of Experience & .13 & .13 & .15 \\
\hline Qualification & $-.20^{* *}$ & $-.17^{* * *}$ & $-.21^{* * *}$ \\
\hline Role based Stress & & $.16^{* *}$ & 12 \\
\hline Self-Efficacy & & $-.43^{* * *}$ & $-.43 * * *$ \\
\hline Moderation & & & $.19^{* * * *}$ \\
\hline $\mathrm{R}^{2}$ & .069 & .320 & .353 \\
\hline Adjusted $R^{2}$ & .040 & .291 & .321 \\
\hline$\Delta \mathrm{R}^{2}$ & .069 & .251 & .034 \\
\hline
\end{tabular}

The result of the moderated hierarchical multiple regression in Table 6 indicate that the demographic variables: gender, marital status, age, years of experience and qualification entered in step 1 of the equation collectively accounted for $6.9 \%$ variance in feeling of reduced personal accomplishment aspect of burnout of nurses with only qualification $(\beta=-.20, p<.01)$ making significant negative contribution to the prediction of feeling of reduced personal accomplishment. This suggests that nurses with low qualification are more likely to experience feeling of reduced personal accomplishment than their counterparts with high qualifications.

In step 2, when the predictor variables: role based stress and self-efficacy were entered as a block, they added significantly to the variance in reduced sense of personal accomplishments aspect of burnout $\left(\Delta R^{2}=.251, F(2,162)=\right.$ 
29.91, $p=.001)$. Individually, role based stress $(\beta=.16, p<.05)$ significantly contributed positively to feeling of reduced personal accomplishments aspect of burnout, also, self-efficacy $(\beta=-.43, p<.001)$ significantly contributed negatively. These indicate that nurses who experienced high role-based stress and with low self-efficacy experienced higher level feeling of reduced personal accomplishment than their counterparts, thereby confirming hypotheses 7 and 8 .

More so, the interaction terms between the moderating (self-efficacy) and predictor (role-based stress) when entered as a block in step 3 of the regression model accounted for $35.3 \%$ variance in feeling of reduced personal accomplishments aspect of burnout $\left(\Delta R^{2}=.034, \Delta F(1,161)=8.34, p<.05, \quad \beta=.19, t(161)=2.89, p<.05\right)$. This significant positive contribution has shown that self-efficacy strengthened the positive relationship between rolebased stress and feeling of reduced personal accomplishment, thus not confirming hypothesis 9 .

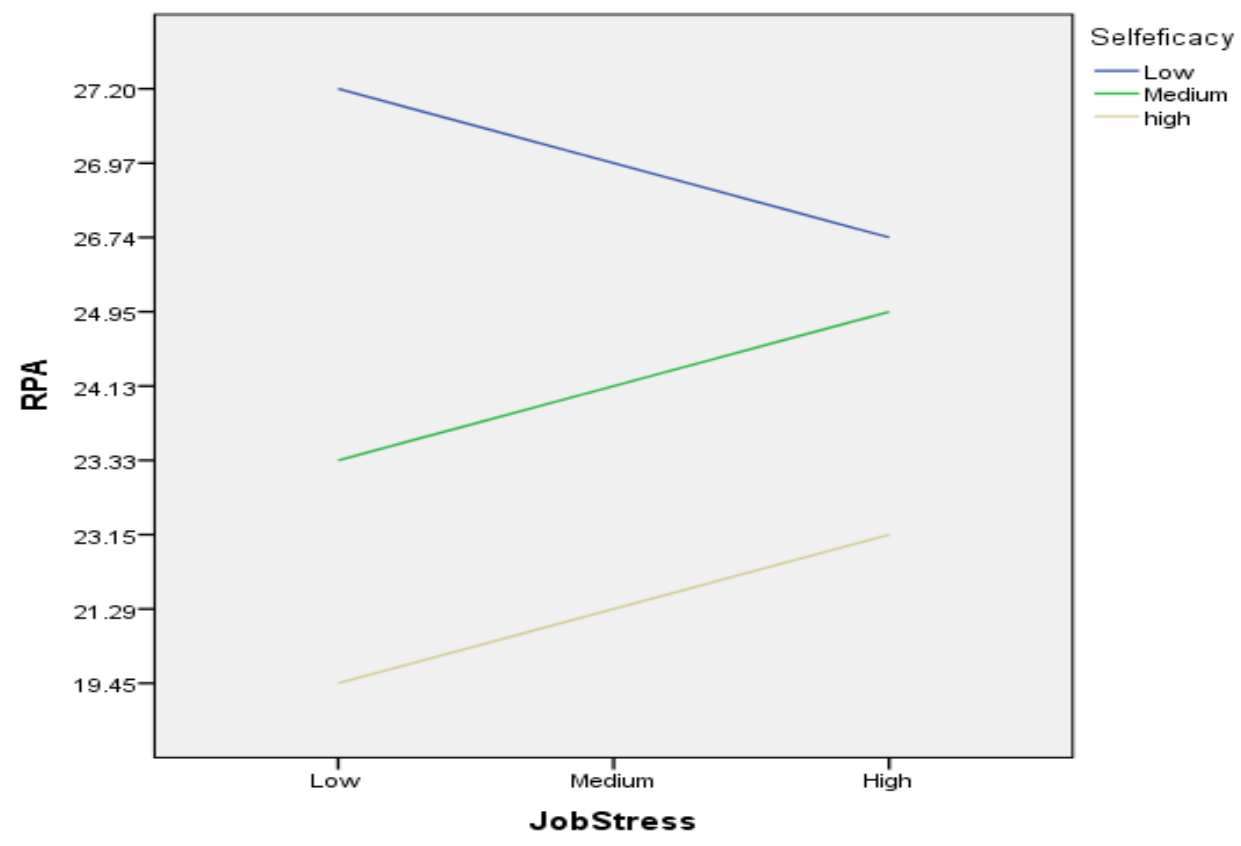

Figure-1. Interaction slope for moderating role of self-efficacy in the relationship between role-based stress and burnout.

Meaning, when self-efficacy is low, there is significant relationship between role-based stress and feeling of reduced personal accomplishments positively, when self-efficacy is at the mean, there is a significant positive relationship between role-based stress and feeling of reduced personal accomplishments, and finally, when selfefficacy is high, there is a significant negative relationship between role based-stress and feeling of reduced personal accomplishments.

\section{DISCUSSION}

Contrary to the first hypothesis, results indicated no relationship between role-based stress and emotional exhaustion component of burnout among the nurses. This shows that experience of role-based stress had no association with experience of burnout of the nurses. And this result showing no association between the variables is not in support of previous studies (e.g.(Maslach et al., 2001; Stordeur et al., 2001)) which found work stressors to be positively associated with emotional exhaustion. This incongruence could be attributed to the assumptions of institutional theory (Scott, 2005) which suggest that institutions and people in other national contexts especially developing countries may be exposed to different factors which influence their management practices. And these management practices in developing countries such as Nigeria may have implications for the outcome of studies involving Nigerian organizations. 
In support of the second hypothesis, results showed negative relationship between self-efficacy and emotional exhaustion component of burnout. Following this, as the nurses' beliefs in their capabilities to exercise control over events that affect their lives (self-efficacy) increased, their experience of emotional exhaustion decreased and vice versa. This negative lends credence to previous studies (e.g. (Aftab et al., 2012; Saleh, 2007; Schaufeli \& Salanova, 2007)) which found negative association between self-efficacy and emotional exhaustion. In contrast, the results which found self-efficacy not to weaken the positive relationship between role-based stress and emotional exhaustion did not support the third hypothesis.

The results have been found to be incongruence with the fourth hypothesis as no relationship was found between role-based stress and dehumanization component of burnout. This is in line with previous study (Enukorah, 2010) in Nigeria which found no significant influence of role stress on burnout. Lending support to the fifth hypothesis self-efficacy negatively related with dehumanization experience of the nurses. This is an indication that having high belief in capabilities to exercise control over events that affect one's life (self-efficacy) associated with low treatment of people as mere objects (dehumanization), thus supporting previous studies (e.g. Bandura (1997)). The results also failed to support the sixth hypothesis as self-efficacy failed to weaken the positive relationship between role-based stress and dehumanization aspect of burnout. And this is not in line with previous studies (e.g. Grau et al. (2001)) which found that self-efficacy to moderate the stress-strain relationships in general, in the sense that low level of self-efficacy are related to high levels of job stress and all dimensions of burnout.

Supporting the seventh hypothesis findings revealed that role-based stress positively related to feeling of reduced sense personal accomplishment aspect of burnout among the nurses. This implies that increase in the stress emanating from the role responsibilities of the nurses increased in the same direction with decline in the nurses' feelings of competence and successful achievements. This further shows that as the nurses role-based stress increased, their feeling of reduced personal accomplishment increased and vice versa. The result gives credence to previous studies (e.g. (Tuna \& Baykal, 2014; Woodhead et al., 2004; Xie et al., 2011)) which reported positive association between role-based stress and feeling of reduced personal accomplishment. In line with hypothesis eight, self-efficacy was found to be negatively related to feeling of reduced personal accomplishment among the nurses. Following this, as the nurses' beliefs in their capabilities to exercise control over events that affect their lives (selfefficacy) increased, feeling of reduced personal accomplishment decreased and vice versa. This is in congruence with earlier view (Cherniss, 1980) that lack of confidence in one's own competence is a critical factor in the development of burnout.

Against hypothesis nine, self-efficacy strengthened the positive relationship between role-based stress and feeling of reduced sense of personal accomplishment among the nurses. This incongruence with previous studies (e.g. Jex and Bliese (1999)) which found that self-efficacy has a moderating role on some pointers of burnout, to the extent that high levels of self- efficacy is related to less burnout, while low level of self-efficacy is related to high burnout.

The results of this present study revealed that role-based stress positively related to feeling of reduced personal accomplishment and self-efficacy negatively related to the three components of burnout strongly lent support to Bakker et al. (2003) job demand-resources model.

\section{IMPLICATION OF THE STUDY}

This study has made theoretical and practical contributions to existing literature.

First, the findings of this present study revealing that role-based stress positively related to feeling of reduced personal accomplishment and self-efficacy negatively related to the three components of burnout have given credence to the contributions of Bakker et al. (2003) job demand-resources theory to the understanding of the relationship between role-based stress, self-efficacy and burnout among nurses. 
Second, the study has paved way for the understanding of the negative role of stress emanating from the role responsibilities of nurses in their feeling of not achieving much despite their immense contributions in healthcare delivery. Considering these, the Nursing Council, Ministry of Health and other organizations saddled with the responsibility of healthcare delivery in Nigeria should make policies that will reduce role-based stress and enhance self-efficacy of nurses in order reduce burnout, hence increasing the quality of healthcare services provided by nurses. This effort in the light of other factors will contribute immensely to the achievement of sustainable development goals.

\section{LIMITATIONS OF THE STUDY}

Although the present study has made relevant theoretical and practical contributions, it has some limitations. First, since the sample size represented only nurses from two hospitals within Enugu urban which is located in Eastern Nigeria, the external validity of the findings is limited; hence the generalization should be done with caution. To this end, future studies in this area should cover nurses in the other states of Nigeria in order to ensure geographical spread. The use of cross-sectional survey and self report could not allow cause-effect relationship. Longitudinal studies and experimentation, therefore, are likely to provide better data and more robust findings.

\section{CONCLUSION}

Role-based stress positively related to feeling of reduced personal accomplishment component of burnout while self-efficacy negatively related to all the components of burnout (emotional exhaustion, dehumanization and feeling of reduced personal accomplishment), hence the need to create work conditions that will reduce role-based stress and enhance self-efficacy in order to prevent burnout and its effects on nurses.

Funding: This study received no specific financial support.

Competing Interests: The authors declare that they have no competing interests.

Acknowledgement: All authors contributed equally to the conception and design of the study.

\section{REFERENCES}

Aftab, N., Ali Shah, A., \& Mehmood, R. (2012). Relationship of self-efficacy and burnout among physicians. Academic Research International, 2(2), 40-49.

Alidosti, M., Delaram, M., Dehgani, L., \& Moghadam, M. M. (2016). Relationship between self-efficacy and burnout among nurses in Behbahan city, Iran. Women's Health Bulletin, 3(4), e30445. Available at: https://doi.org/10.17795/whb30445 .

Anderson, D. G. (2013). Coping strategies and burnout among veteran child protection workers. Child Abuse $\mathcal{E}^{2}$ Neglect, 20(6), 839-840.

Anomneze, E. A., Ugwu, D. I., Enweruzor, I. K., \& Ugwu, L. I. (2016). Teachers' emotional labour and burnout: Does perceived organizational labour matter? Asian Social Science, 12(2), 9-22. Available at: https://doi.org/10.5539/ass.v12n2p9.

Bakker, A. B., Demerouti, E., \& Schaufeli, W. B. (2003). Validation of the Maslach burnout inventory-general survey: An internet study. Anxiety, Stress \& Coping, 15(3), 245-260. Available at: https://doi.org/10.1080/106158002 10000207 16.

Bandura, A. (1997). Self-efficacy: The exercise of control. New York: Freeman.

Brief, A. P., \& Aldag, R. J. (1989). The self in work organization: Conceptual review. Journal of Management Review, 6, 75-88.

Cherniss, C. (1980). Staff burnout: Job stress in the human services. Beverly Hills: Sage.

Coker, A. O. (1999). Assessment of burnout syndrome in doctors and nurses. Unpublished M.sc research project, Department of Psychology University of Lagos.

Cordes, C. L., \& Dougherty, T. W. (1993). A review and an integration of research on job burnout. Academy of Management Review, 18(4), 621-656. Available at: https://doi.org/10.2307/258593. 
Cropanzano, R., Rupp, D. E., \& Byrne, Z. S. (2003). The relationship of emotional exhaustion to work attitudes, job performance, and organizational citizenship behaviors. Journal of Applied Psychology, 88(1), 160-169. Available at: https://doi.org/10.1037/0021-9010.88.1.160.

Elisburg, D. (1995). Workplace stress: Legal development, economic pressures and violence. In J.F Burton (Eds), workers compensation year book. New York: MCGraw Hill.

Enukorah, F. (2010). Role of stress and age on psychological burnout among nurses. Nigerian Journal of Psychological Research, $6(1), 75-82$.

Eze, I. (2014). Influence of perceived organizational support and self-efficacy on burnout. Research on Humanities and Social Science, $4(24), 40-47$.

Eze, A. C. (2019). Job characteristics and work-to-family conflict relations: The moderating role of core self-evaluations among married female bankers in Enugu metropolis. Unpublished Ph.D Thesis, Department of Psychology, Enugu State University of Science and Technology, Nigeria.

Freudenberger, H. J. (1974). The staff burnout. Journal of Social Science Issues, 30(1), 159-165.

Garrosa, E., Moreno-Jiménez, B., Rodríguez-Muñoz, A., \& Rodríguez-Carvajal, R. (2014). Role stress and personal resources in nursing: A cross-sectional study of burnout and engagement. International Journal of Nursing Studies, 48(4), 479-489. Available at: https://doi.org/10.1016/j.ijnurstu.2010.08.004.

Grau, R., Salanova, M., \& Peiró, J. M. (2001). Moderator effects of self-efficacy on occupational stress. Psychology in Spain, 5(1), 63-74.

Hahn, V., Binnewies, C., Sonnentag, S., \& Mojza, E. (2011). Learning how to recover from job stress: Effects of a recovery training program on recovery, recovery-related self-efficacy, and well-being. Journal of Occupational Health Psychology, 16(2), 202-2 16. Available at: https://doi.org/10.1037/a0022 169.

Hobfoll, S. E. (1988). The ecology of stress. New York: Hemisphere.

Hobfoll, S. E. (1989). Conservation of resources: A new attempt at conceptualizing stress. American Psychologists, 44(3), 5-10. Available at: https://doi.org/10.1037/0003-066x.44.3.513.

Jackson, S. E., Schwab, R. L., \& Schuler, R. S. (1986). Toward an understanding of the burnout phenomenon. Journal of Applied Psychology, 71(4), 630-640. Available at: https://doi.org/10.1037/0021-9010.71.4.630.

Jex, S. M., \& Bliese, P. P. (1999). Efficacy beliefs as a moderator of the impact of work- related stressor: Multilevel study. Journal of Applied Psychology, 84, 349-361. Available at: https://doi.org/10.1037/002 1-9010.84.3.349.

Jimmieson, N. L., Terry, D. J., \& Callan, V. J. (2004). A longitudinal study of employee adaptation to organizational change: The role of change related information and change-related self efficacy. Journal of Occupational Health Psychology, 9, 11-27. Available at: https://doi.org/10.1037/1076-8998.9.1.11.

Kahn, R., \& Byosiere, P. (1997). Stress in organization. In M.,dunnette and L.M, hough (Eds). Handbook of industrial and organizational psychology. Palo Allo,CA: Consulting Psychologist Press.

Kahn, R. L., Wolfe, D. M., Quinn, R. P., Snoek, J. D., \& Rosenthal, R. (1964). Organizational stress: Studies in role conflict and ambiguity. New York: Wiley.

Kelly, L. Z., Wanyne, A. H., Pamela, L. P., Angela, K. M., \& Christian, K. (2001). Beyond self-efficacy: Interactive effects of role conflicts and perceived collective efficacy. Journal of Managerial Issues, 13(4), 483-499.

Kirwan, M., \& Armstrong, D. (1995). Investigation of burnout in a sample of British general practitioners. British General Practitioners, 45(394), 259-260.

Lee, R. T., \& Ashforth, B. E. (1990). A meta-analytic examination of the corrections of the three dimensions of job burnout. Journal of Applied Psychology, 81(2), 123-133. Available at: https://doi.org/10.1037/002 1-90 10.81.2.123.

Lee, R. T., \& Ashforth, B. E. (1996). A meta-analytic examination of the corrections of the three dimensions of job burnout. Journal of Applied Psychology, 81, 123-133. Available at: https://doi.org/10.1037/0021-9010.81.2.123.

Leiter, M. P., \& Maslach, C. (1988). The impact of interpersonal environment on burnout and organizational commitment. Journal of Organizational Behavior, 9(4), 297-308. Available at: https://doi.org/10.1002/job.4030090402. 
Lu, L., Yueh, C. Y., \& Lune, L. S. (2011). What differentiates success from strain: The moderating effects of self -efficacy. International Journal of Stress and Management, 18(4), 396-412. Available at: https://doi.org/10.1037/a0025122.

Maslach, C., \& Jackson, S. (1986). The measurement of experienced burnout. Journal of Occupational Behaviour, 2(1), 99-113.

Maslach, C., Schaufeli, W. B., \& Leiter, M. P. (2001). Job burnout. Annual Review of Psychology, 52(1), 397-422.

Maslach, C., \& Jackson, S. E. (1981). The measurement of experienced burnout. Journal of Organizational Behavior, 2(2), 99-113.

Morana, T., Branko, K., Dinko, S., \& Vanja, T. (2014). Stress, depression and burnout among hospital physicians in Rijeka, Croatia. Psychiatria Danubia, 26(3), 450-458.

Niosh, R. (1995). Nursing stress. Retrieved from: http://www.Cdc.gov/Niosh/stresswk.html. [ Accessed February 2017].

Nwabuoku, U. C., \& Adebayo, S. O. (2010). Burnout, empowerment and job satisfaction of human service: A comparative study of women. The Social Science Journal, 5(4), 276-279.

Okonkwo, E. (2013). Psychology of work. Enugu Nigeria: Ofiaco Productions.

Okonkwo, E. A. (2014). Work-family conflict bi-directions and burnout among female teachers in Enugu, Nigeria. Contemporary Journal of Applied Psychology, 1(2), 75-87.

Okonkwo, E. A., Onuibe, B. N., Okoro, C. M., \& Madu, O. E. (2015). Influence of task andlocation on emotional exhaustion among university workers. Global Journal of Applied Management and Social Sciences, 8(1), 43-48.

Okonkwo, E. A., Egbujor, V. U., \& Onyeneje, E. C. (2018). Moderating role of locus of controlin job stress and job involvement relationship. Nigerian Journal of $\quad$ Psychological Research, 14(1), 52-60.

Olebara, C., \& Okonkwo, E. A. (2019). Moderating role of career growth prospects in burnout-job involvement link among female nurses. Journal of Nursing and Health Science, 8(3), 73-79.

Oseghare, C. K. (1988). An evaluation study of mclean's stressor checklist. Unpublished M.Sc Thesis University of Lagos, Nigeria.

Pines, A. M., \& Aronson, E. (1988). Career burnout: Causes and ures. New York: Free Press.

Pisanti, R., Van der Doef, M., Maes, s., Lombardo, C., Lazzari, D., \& Violani. (2015). Occupational coping self-efficacy explains distress and wellbeing in nurses beyond psychosocial job characteristics. Frontiers in Psychology, 6(11), 43-50. Available at: https://doi.org/10.3389/fpsyg.2015.01143.

Salanova, M., Peiro, J. M., \& Schaufeli, W. B. (2002). Self-efficacy specificity and burnout among information technology workers: Extension of the job demand control model. European Journal of Work and Organizational Psychology, 11(1), 125. Available at: https://doi.org/10.1080/13594320143000735

Saleh, Z. (2007). Malaysian governmental accounting: National context and user orientation. International Review of Business Research Papers, 3(2), 376-384.

Schaufeli, W. B., \& Greenglass, E. R. (2001). Introduction to special issue on burnout and health. Psychology $\S^{2}$ Health, 16(5), 501510. Available at: https://doi.org/10.1080/08870440108405523.

Schaufeli, W. B., \& Salanova, M. (2007). Efficacy or inefficacy, that's the question: Burnout and work engagement, and their relationships with efficacy beliefs. Anxiety, Stress, and Coping, 20(2), 177-196. Available at: https://doi.org/10.1080/10615800701217878.

Schwarzer, R. (1999). Assessment of perceived general self-efficacy on the internet: Data collection in cyberspace. Anxiety, Stress E Coping, 12(2), 145-161.

Schwarzer, R., \& Jerusalem, M. (1995). Generalized self-efficacy. In J.Weinman, S,Wright, \& M Johnston, Measures in health psychology: A user's portfolio. Causal and Control Beliefs, 35-37, Windor, England: NFER-NELSON.

Scott, W. R. (2005). Institutional theory: Contributing to a theoretical research program in great minds in management: The process of theory development, eds. K.G. Smith and M.A. Hitt (pp. 460-484). New York: Oxford University Press.

Shoji, K., Cieslak, R., Smoktunowicz, E., Rogala, A., Benigh, C. C., \& Luszczynska, R. (2016). Association between job burnout and self-efficacy a meta-analysis. Anxiety, Stress and Coping: An International Journal, 10(3), 40-48.

Stordeur, S., D'hoore, W., \& Vandenberghe, C. (2001). Leadership, organizational stress, $\quad$ and emotional exhaustion among hospital nursing staff. Journal of Advanced Nursing, 35(4), 533-542. Available at: https://doi.org/10.1046/j.1365-2648.2001.01885.x. 
Thompson, \& Gomez, R. (2014). The role of self esteem and self-efficacy in moderating the effect of workplace stress on depression, anxiety and stress. Australasian Journal of Organizational Psychology, 7(2), 40-50. Available at: https://doi.org/10.1017/orp.2014.2.

Togia, A. (2005). Measurement of burnout and the influence of background characteristics in Greek academic librarians. Library Management, 26(3), 130-138. Available at: https://doi.org/10.1 108/01435120510580870.

Tuna, R. S., \& Baykal, U. (2014). The relationship between job stress and burnout levels of oncology nurses. Asia Pacific Journal of Oncology Nursing, 1(1), 33-39. Available at: https://doi.org/10.4103/2347-5625.135818.

Tunde, A. O., \& Onabanjo, O. C. (2013). Influence of personality and self-esteem on teachers' proneness to burnout syndrome in lagos metropolis. American Journal of Applied Psychology, 1(1), 7-13.

Winefield, H., \& Anstey, T. J. (1991). Job stress in general practice: Practitioner age, sex and attitudes as predictors. Family Practice, 8(2), 140-144. Available at: https://doi.org/10.1093/fampra/8.2.140.

Winstanley, S., \& Whittington, R. (2002). Anxiety, burnout and coping style in general hospital staff exposed to work aggressions: A cyclical model of burnout and vulnerability to aggression. Work and Stress, 16, 302-315. Available at: https://doi.org/10.1080/0267837021000058650.

Woodhead, E. L., Northrop, L., \& Edelstein, P. (2004). Occupational stress, social support and burnout among long term care nursing staff. Journal of Applied Gerontology, 35(1), 84-105. Available at: https://doi.org/10.1 177/07334648 14542465.

Wright, T. A., \& Bonnet, D. G. (1997). The contribution of burnout to work performance. Journal of Organizational Behavior, 18, 491-499. Available at: https://doi.org/10.1002/(sici)1099-1379(199709)1 8:5<491::aid-job804>3.0.co;2-i.

Wright, J., Scott, H., \& Rose, J. (2015). Investigating predictors and moderators of burnout in staff working in services for people with intellectual disabilities: The roles of emotional intelligence, exposure to violence and self-efficacy. International Journal of Developmental Disabilities, 5(10), 40-45.

Xie, Z., Wang, A., \& Chen, B. (2011). Nurses burnout and its association with occupational stress in a cross sectional study in Shanghai. Journal of Advance Nursing, 67(7), 1537-1546.

Views and opinions expressed in this article are the views and opinions of the author(s), International Journal of Social and Administrative Sciences shall not be responsible or answerable for any loss, damage or liability etc. caused in relation to/arising out of the use of the content. 